\title{
Isolation and functional analysis of syndecans
}

\author{
Pyong Woo Park ${ }^{1}$ \\ Boston Children's Hospital, Harvard Medical School, Boston, MA, United States
}

\begin{abstract}
Syndecans comprise a major family of cell surface heparan sulfate proteoglycans (HSPGs). Syndecans are composed of sulfated glycosaminoglycans (GAGs), heparan sulfate (HS) or both HS and chondroitin sulfate (CS), attached covalently to core proteins. Syndecans regulate many cellular processes, such as adhesion, proliferation, and migration. Syndecans bind and regulate molecules primarily through their HS chains, but do not bind to all HS/heparin-binding molecules. Furthermore, mice ablated for the syndecan- 1 or -4 gene do not show major developmental abnormalities, but they do show striking pathological phenotypes when challenged with infectious or inflammatory stimuli and conditions, suggesting that certain functions of syndecans are specific and cannot be compensated for by other syndecans or other HSPGs. These observations underscore the physiological importance of syndecans and indicate a need to study the activities of isolated native syndecans to define their molecular and cellular functions, and to establish their biological significance. Here we describe methods to isolate syndecans and several assays to analyze their functions.
\end{abstract}

\section{INTRODUCTION}

Syndecans are type I transmembrane proteoglycans with GAG chains attached covalently to specific Ser residues in syndecan core proteins (Bernfield et al., 1992; Couchman, 2010; Park, Reizes, \& Bernfield, 2000). Syndecan core proteins have a similar domain structure, each with an extracellular domain that harbors GAG chains, and highly conserved transmembrane and cytoplasmic domains that mediate multimerization and interaction with several cytoplasmic proteins, respectively. Syndecans contain HS or both HS and CS chains, which endow syndecans with unique biochemical and functional properties. Syndecan-1 (CD138) was the first syndecan isolated from normal murine mammary gland (NMuMG) epithelial cells (Rapraeger \& Bernfield, 1983) and rat livers (Kjellen, Pettersson, \& Hook, 1981), and was the first syndecan whose gene was cloned (Saunders, Jalkanen, O'Farrell, \& Bernfield, 1989). Isolation and cloning of other syndecans soon followed, and we now know that there are four syndecans in mammals (Bernfield et al., 1992; Couchman, 2010).

Syndecans are expressed on different cell types and locations at different times and levels and, hence, likely perform specific functions in vivo (Bernfield et al., 1999, 1992; Kim, Goldberger, Gallo, \& Bernfield, 1994). For example, syndecan-1 is detected at the four-cell stage during mouse development, indicating that expression is zygotically activated

${ }^{1}$ Corresponding author: pyong.park@ childrens.harvard.edu. 
(Sutherland et al., 1991). In adult tissues, syndecan-1 is predominantly expressed on the surface of epithelial cells and plasma cells (Bernfield et al., 1999, 1992; Hayashi et al., 1987; Kim et al., 1994). In fact, syndecan-1 is used as a specific marker for plasma cells and multiple myeloma cells (Wijdenes et al., 1996).

Syndecans function primarily as coreceptors at the cell surface (Bernfield et al., 1999; Park et al., 2000). Syndecans can also function as soluble HSPGs since the intact extracellular ectodomain, replete with GAG chains, can be released from the cell surface in a proteolytic process known as ectodomain shedding (Bernfield et al., 1999; Park et al., 2000). Cells in culture shed their syndecan ectodomains constitutively, but syndecan shedding can also be rapidly and significantly accelerated. For example, syndecan- 1 shedding is induced in vitro by several inflammatory factors and in vivo under certain pathologic conditions, and syndecan-1 ectodomains are thought to modulate the onset, progression, and resolution of several infectious, inflammatory, and oncogenic diseases (Teng, Aquino, \& Park, 2012). Surprisingly, mice lacking syndecan-1 or -4 do not show any major developmental abnormalities (Alexander et al., 2000; Echtermeyer et al., 2001; Ishiguro et al., 2001; Park, Pier, Hinkes, \& Bernfield, 2001). However, they show striking pathological phenotypes when injured or infected (Echtermeyer et al., 2001; Hayashida, Bartlett, Foster, \& Park, 2009; Hayashida, Chen, Bartlett, \& Park, 2008; Hayashida, Parks, \& Park, 2009; Haynes et al., 2005; Ishiguro et al., 2001; Kharabi Masouleh et al., 2009; Li, Park, Wilson, \& Parks, 2002; Park et al., 2001; Rops et al., 2007; Vanhoutte et al., 2007; Xu, Park, Kheradmand, \& Corry, 2005), suggesting that certain postdevelopmental functions of syndecans are specific and cannot be compensated for by other syndecans or other HSPGs.

HS and heparin bind and regulate many molecules, such as growth factors, cytokines, chemokines, morphogens, antimicrobial peptides (AMPs), microbial proteins, and ECM components, among others (Bernfield et al., 1999; Bishop, Schuksz, \& Esko, 2007; Teng et al., 2012). HS binds specifically to these molecules and can either inhibit or potentiate their functions by affecting their activity, stability, conformation, or destination. Syndecans primarily bind to ligands through their HS chains, but they do so in a selective manner. For example, syndecan-1 binds to several HS/heparin-binding proteins, such as FGF-2, fibronectin, thrombospondin, tenascin, and type I, III, and V interstitial collagens, but not to others, including type IV collagen, laminin, vitronectin, and many more (Elenius, Salmivirta, Inki, Mali, \& Jalkanen, 1990; Kato, Wang, Bernfield, Gallagher, \& Turnbull, 1994; Salmivirta et al., 1991; Saunders \& Bernfield, 1988; Sun, Mosher, \& Rapraeger, 1989). One of the major gaps in our understanding of syndecan biology centers on how syndecans bind specifically to certain HS/heparin-binding molecules but not to others, and how these syndecan interactions modulate biological processes in health and disease.

\section{ISOLATION OF SYNDECANS}

\subsection{SYNOPSIS}

Native syndecans can be isolated from tissues, cultured cells, and conditioned medium (CM) of cultured cells using methods that take advantage of the presence of sulfated GAG moieties and specific antibodies directed against the core protein domains. Similar to the isolation of other native proteoglycans, procedures to isolate native syndecans are rather 
time consuming and generally yield low amounts. Alternate approaches to increase the yield include overexpressing syndecan core protein genes in cell lines using strong promoters (e.g., CMV) and viral vectors (e.g., adenovirus or lentivirus) and/or tagging the syndecan expression construct. However, overexpression usually overwhelms the GAG biosynthetic pathway and results in underglycosylated and undersulfated syndecans, which will certainly affect their biological activities. Tagging syndecan constructs at the $\mathrm{C}$-terminus interferes with their correct processing and targeting (Maday et al., 2008), and tagging at the Nterminus may also interfere with syndecan functions since the major ligand-binding $\mathrm{HS}$ chains are attached near the N-terminus in all four syndecans. However, syndecan-1 Histagged at the $\mathrm{N}$-terminus has been shown to retain its ability to bind to death receptor 6 (Fujikura et al., 2017), suggesting that $\mathrm{N}$-terminal tagging may not interfere with activity, although the activity and HS structure of tagged syndecan-1 were not rigorously compared to those of the native counterpart.

We describe here a relatively simple procedure for isolating syndecan ectodomains from the $\mathrm{CM}$ of NMuMG epithelial cells. NMuMG cells are used for many syndecan-related studies because they express all four syndecans (Kim et al., 1994) and are relatively easy to culture and manipulate. NMuMG cells constitutively shed all four syndecan ectodomains into the culture medium. The CM of NMuMG cells contains approximately $80-100 \mu \mathrm{g} / \mathrm{L}$ of

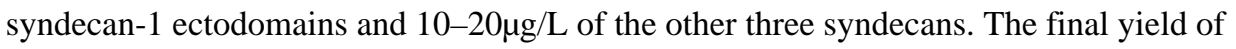
purified syndecan ectodomains is approximately $20 \%-30 \%$ for syndecan-1 and $10 \%-20 \%$ for other syndecans. The scale of the starting material should be adjusted based on the amount of purified syndecans needed for subsequent experiments.

The purification procedure, described in detail below, involves isolation of total proteoglycans by strong anion-exchange (SAX) chromatography and purification of syndecans by immunoaffinity chromatography using specific antibodies directed against the respective core proteins. SAX chromatography takes advantage of the property that GAGs have a high net negative charge contributed by the sulfate and carboxyl groups of these glycans. SAX chromatography is performed under acidic conditions ( $\mathrm{pH} 4.5$ ) to isolate proteoglycans, including syndecans, that contain sulfated GAG chains with a pI of 2-4. Close to $100 \%$ of the syndecans in the CM should be recovered and partially purified by SAX chromatography. If needed, the $\mathrm{pH}$ of the binding buffer can be further lowered or a $\mathrm{CsCl}$ density gradient ultracentrifugation step can be added after SAX chromatography to select for syndecans with longer, highly sulfated HS chains. Proteoglycans with two or more sulfated GAG chains have very high molecular densities, owing to the high specific gravity of GAGs. Proteoglycans bound to the SAX resins are eluted with $4 \mathrm{M}$ guanidinium $\mathrm{HCl}$ $(\mathrm{GuHCl})$ or $2 \mathrm{M} \mathrm{NaCl}$, desalted and buffer exchanged by Sephadex G-25 chromatography, and concentrated by lyophilization or by ultrafiltration prior to immunoaffinity chromatography.

Anti-syndecan antibodies are coupled to affinity resins, of which many are available from commercial sources. For mouse syndecan- 1 and -4 , we use the 281-2 and Ky8.2 rat monoclonal anti-mouse syndecan- 1 and -4 antibodies, respectively, and for syndecan- 2 and -3 , we use custom-made rabbit polyclonal antibodies made against recombinant syndecan-2 and -3 core proteins. Other monoclonal and polyclonal anti-mouse and anti-human syndecan 
antibodies are available commercially, but we have not tried these in the immunoaffinity purification of syndecans. We covalently couple anti-syndecan antibodies via primary amines to Ultralink. Several affinity resins that couple ligands through similar chemistry are commercially available, but we use Ultralink based on its relative ease of use, high coupling efficiency, durability, and its ability to withstand ligand leakage compared to other affinity resins. Anti-syndecan antibodies are coupled to Ultralink and the resins blocked per manufacturer's instructions, washed with elution buffer, and equilibrated with binding buffer prior to use. The proteoglycan preparation from SAX chromatography is applied to the affinity resin, washed extensively, and eluted with 100mM Gly (pH 10), 100mM triethanolamine ( $\mathrm{pH} 11)$, or 50mM Tris, $\mathrm{pH} 7.4$ with $7 \mathrm{M}$ urea. In our hands, high $\mathrm{pH}$ buffers and $7 \mathrm{M}$ urea are more effective than low $\mathrm{pH}$ buffers in eluting syndecans from immunoaffinity resins. Furthermore, the Ultralink immunoaffinity resins can be regenerated and reused even after 7M urea elution with extensive washes with neutral buffer.

The purity of immunoaffinity-purified syndecan ectodomains is analyzed by silver staining and amino acid composition analysis. Purity of syndecans isolated by this method is generally $\geq 90 \%$. The concentration of purified syndecans is determined by amino acid composition analysis, dot immunoblotting using previously purified native syndecans as standards, and by measuring $\mathrm{OD}_{280 \mathrm{~nm}}$. Commercial ELISA kits for several syndecans are available, but caution must be taken when using these kits to estimate the amount of purified syndecans. These kits generally use recombinant syndecans as standards, and tend to overestimate the concentration of isolated native syndecan ectodomains by 10 -fold or more.

Purified syndecan ectodomains are further analyzed by Western immunoblotting. Intact syndecan ectodomains, replete with GAG chains, bind poorly to conventional protein blotting membranes, such as nitrocellulose and PVDF, because the highly anionic GAGs interfere with membrane binding. Instead they bind efficiently to positively charged membranes used generally for nucleic acid analyses, such as positively charged nylon. We have tested several positively charged membranes and found that Immobilon $\mathrm{Ny}+$ works best for Western immunoblotting of both mouse and human syndecans. On the other hand, once the GAG chains are removed by GAG lyase digestion, $\beta$-elimination, or nitrous acid degradation, syndecan core proteins bind efficiently to PVDF and nitrocellulose membranes. To avoid potential adverse effects of chemical GAG removal on the antigenic epitope in syndecan core proteins, we generally remove GAGs from purified syndecans by heparinase II and chondroitinase $\mathrm{ABC}$ digestion to analyze the syndecan core protein by Western immunoblotting. Fig. 1A shows the immunoblotted proteoglycan smears of purified native mouse syndecan- 1 and -4 ectodomains, and Fig. 1B shows the immunoblotted core protein bands of purified native syndecan- 1 and -4 ectodomains digested with GAG lyases. Note that both syndecan-1 and -4 ectodomain core proteins migrate as higher molecular entities than their predicted sizes (Fig. 1B). The predicted sizes for mouse syndecan ectodomain core proteins are approximately $24 \mathrm{kDa}$ for syndecan-1, $14 \mathrm{kDa}$ for syndecan-2, 35kDa for syndecan-3, and 13kDa for syndecan-4, but they migrate as 70-90, 40-50, 90-120, and 3040kDa bands, respectively, in SDS-PAGE. Syndecans contain the GxxxG dimerization motif (Dews \& Mackenzie, 2007), and both multimerization and high Pro content (e.g., 10.4\% and $10.7 \%$ in syndecan- 1 and -4 ectodomains, respectively) in syndecan core proteins have been proposed as the cause of aberrant migration in SDS-PAGE (Bernfield et al., 1992). However, 
the dimerization motif is contained in the transmembrane domain, which is absent in purified syndecan ectodomains. Moreover, recombinant syndecan ectodomains devoid of GAG chains also migrate as higher molecular mass bands, suggesting that the extended conformation due to high Pro content is the likely cause of aberrant migration in SDSPAGE.

\subsection{ISOLATION}

\subsubsection{Preparation of conditioned medium}

1. Collect CM from NMuMG cell cultures (ATCC, Sigma, Fisher). Cells should be plated at approximately 40\%-50\% and the CM should be collected when cells are confluent. Passage cells and repeat until sufficient amounts of CM are collected. Add sodium azide $(0.05 \%)$ to the collected $\mathrm{CM}$ and store at $-20^{\circ} \mathrm{C}$ until use. We generally collect 6-10L of CM per isolation procedure.

2. Thaw the frozen $\mathrm{CM}$ and centrifuge at $10,000 \times g$ for $20 \mathrm{~min}$. Filter through a fiber glass wool (Corning, Fisher) using a funnel. Transfer filtered CM to an autoclaved large bucket and add a stir bar.

3. Add urea gradually to $7 \mathrm{M}$ while stirring. Dissolving urea is endothermic so depending on the volume of the CM, it will take several hours to dissolve.

4. Add sodium acetate $(\mathrm{NaOAc})$ to $100 \mathrm{mM}$ and adjust $\mathrm{pH}$ to 4.5 with glacial acetic acid. $\mathrm{CM}$ will change color from pink to yellow when the $\mathrm{pH}$ is correctly adjusted. It is also good practice to confirm the $\mathrm{pH}$ of the $\mathrm{CM}$ with a $\mathrm{pH}$ paper. Save a small aliquot $(\sim 1 \mathrm{~mL})$ for later use (e.g., to determine the exact syndecan concentrations in starting material and yield of purified syndecans).

\subsubsection{Q-Sepharose SAX chromatography}

1. Prepare Q-Sepharose Fast-Flow SAX resins (GE Healthcare Life Sciences). We generally use $10 \mathrm{~mL}$ resin per $1 \mathrm{~L}$ of $\mathrm{CM}$ up to $50 \mathrm{~mL}$ of resin. Transfer the appropriate volume of Q-Sepharose resin to glass columns (e.g., glass econocolumns, Bio-Rad Laboratories). Wash first with 3 resin volumes of $100 \mathrm{mM} \mathrm{NaOH}$ and then equilibrate with $\geq 10$ resin volumes of binding buffer (100mM NaOAc, pH 4.5, 150mM NaCl, 7M urea). We prepare all solutions in autoclaved deionized water without protease inhibitors.

2. Apply acidified CM samples to the Q-Sepharose column by gravity flow. Collect flow through and reapply to column, repeat $\geq 3$ times. Save unbound material.

3. Wash with $\geq 10$ times resin volume of binding buffer. Save wash.

4. Carefully add 0.5 bed volume of elution buffer (4M GuHCl, 50mM Tris, $\mathrm{pH} 7.4$, or $2 \mathrm{M} \mathrm{NaCl}$ ) and discard eluate. Then carefully add 2.5 bed volume of elution buffer and collect eluate in one batch. Alternately, one can elute bound proteoglycans with a $0.5-2 \mathrm{M}$ gradient of $\mathrm{NaCl}$. However, batch elution is sufficient to recover all bound syndecans from the SAX resin. 
5. Desalt and buffer exchange eluted samples by Sephadex G-25 chromatography (GE Healthcare Life Sciences) into TBS (50mM Tris, pH 7.4, 150mM NaCl). Incubate an appropriate amount of Sephadex G-25 powder in autoclaved hot water to preswell the beads and apply to glass columns with appropriate length and diameter. We generally use columns $230 \mathrm{~cm}$ for sample volumes $\geq 10 \mathrm{~mL}$. Alternately, eluates from SAX chromatography can be dialyzed $3 \times$ vs $3 \mathrm{~L}$ of TBS and concentrated by ultrafiltration using 10kDa MWCO tubes (e.g., Macrosep or Jumbosep centrifugal ultrafiltration devices, Pall Laboratory) or dialyzed into autoclaved deionized water and concentrated by lyophilization. The sample volume should be adjusted to $10-20 \mathrm{~mL}$ in TBS prior to immunoaffinity chromatography.

\subsubsection{Immunoaffinity chromatography}

1. Couple protein A/G-purified anti-syndecan antibodies to Ultralink per manufacturer's instructions (Pierce, Fisher). We use 281-2 rat monoclonal antimouse syndecan-1 antibody (Biolegend), Ky8.2 rat monoclonal anti-mouse syndecan-4 antibody (BD Pharmingen), and custom-made rabbit polyclonal antibodies against recombinant mouse syndecan- 2 and -3 . Note that the antibody preparation must be free of buffers containing primary amines (e.g., Tris, Gly) prior to coupling to Ultralink. When attempting to purify $\geq 100 \mu \mathrm{g}$ of syndecans, we generally couple $23 \mathrm{mg}$ of anti-syndecan antibodies to $2 \mathrm{~mL}$ of Ultralink.

2. Apply affinity resin to plastic columns (e.g., poly-prep polypropylene chromatography columns, Bio-Rad Laboratories). Condition resin with 5 bed volumes of affinity elution buffer (100mM Gly, pH 10,100mM triethanolamine, $\mathrm{pH} 11$, or $50 \mathrm{mM}$ Tris, $\mathrm{pH} 7.4$ with $7 \mathrm{M}$ urea). Equilibrate affinity resin with $\geq 20$ volumes of TBS.

3. Using a peristaltic pump (GE Healthcare Life Sciences), apply the partially purified syndecan samples to the affinity column. Apply at a flow rate of 1$1.5 \mathrm{~mL} / \mathrm{min}$ and recirculate $\geq 5$ times. Collect and save unbound material.

4. Wash with $\geq 20 \times$ bed volume of TBS at a flow rate of $1-1.5 \mathrm{~mL} / \mathrm{min}$. Save wash.

5. Elute bound syndecans with one of the three elution buffers. All three elution buffers elute similar amounts of syndecans. We first apply 0.5 bed volumes of elution buffer and do not collect this eluate. We then apply 3 bed volumes of elution buffer and collect the eluate in one batch into a tube containing 0.5 bed volume of $1 \mathrm{M}$ Tris, $\mathrm{pH}$ 7.4.

6. Dialyze (e.g., with Spectra/Por dialysis membranes, Spectrum Medical via Fisher) purified syndecans into TBS or autoclaved deionized water if planning to concentrate by lyophilization.

7. Estimate the concentration of isolated syndecans by measuring $\mathrm{OD}_{280 \mathrm{~nm}}$ or by dot immunoblotting using previously purified syndecans as standards (see below). Based on the extinction coefficient and molecular mass of mouse syndecan ectodomains, $1\left(\mathrm{OD}_{280}\right)=2.18 \mathrm{mg} / \mathrm{mL}$ for syndecan $-1,2.33 \mathrm{mg} / \mathrm{mL}$ for 
syndecan-2, $4.14 \mathrm{mg} / \mathrm{mL}$ for syndecan-3, and $8.96 \mathrm{mg} / \mathrm{mL}$ for syndecan- 4 ectodomains. If available, use nanodrop spectrophotometers (Fisher) to minimize sample usage.

8. Determine the purity of isolated syndecan ectodomains by SDS-PAGE and silver staining (e.g., silver staining kit for mass spectrometry, Fisher), and by amino acid composition analysis. Protein core facilities at several institutions perform amino acid analyses on a fee-for-service basis. Approximately 100ng of syndecans separated by $4 \%-15 \%$ gradient gels can be visualized by silver staining. Immediately stop the silver staining reaction when a nice long proteoglycan smear becomes visible. Multiple sharp protein bands should not be visible if isolated syndecans are pure. For amino acid composition analysis, hydrolyze approximately $2 \mu \mathrm{g}$ of purified syndecans in $6 \mathrm{~N} \mathrm{HCl}$ overnight at $100^{\circ} \mathrm{C}$ in glass tubes and send out for analysis.

\subsubsection{Immunoblotting of syndecans}

1. For dot immunoblotting estimation of syndecan concentrations, add previously purified syndecan standards and several dilutions of sample to the dot-blot apparatus (e.g., Whatman minifold I dot-blot system, Fisher) with Immobilon Ny + membranes (Millipore, Fisher) inserted. Slowly apply house vacuum to bind samples onto the Immobilon $\mathrm{Ny}+$ membrane. Wash the dot-blot wells $3 \times$ with $200 \mu \mathrm{L}$ TBS using house vacuum. For mouse syndecan- 1 and -4 , amounts as low as $0.1 \mathrm{ng}$ can be detected with the 281-2 and Ky8.2 anti-syndecan- 1 and -4 antibodies. The linear range of detection is usually between 0.1 and $1.5 \mathrm{ng}$, which should be the range of syndecan standards used in this assay.

2. Remove the dot-blotted Immobilon Ny+ membrane, wash $3 \times$ with TBS, and then incubate with $10 \%(\mathrm{w} / \mathrm{v})$ nonfat dry milk in TBS for $\geq 2 \mathrm{~h}$ with agitation at room temperature. Wash $2 \times$ with TBS containing $0.5 \%$ nonfat dry milk and $0.1 \%$ Tween-20 at room temperature (30min each). Incubate with primary antisyndecan antibodies in TBS containing $0.5 \%$ nonfat dry milk and $0.1 \%$ Tween- 20 overnight with agitation at $4{ }^{\circ} \mathrm{C}$. Although incubation with the primary antibodies can be shortened to $1-2 \mathrm{~h}$ at room temperature, overnight incubation at $4^{\circ} \mathrm{C}$ reduces background. The dilution of primary antibodies should be titrated by each lab, but a starting point is $0.2 \mu \mathrm{g} / \mathrm{mL}$ for $281-2$ anti-syndecan- 1 and Ky8.2 anti-syndecan- 4 antibodies and $1 \mu \mathrm{g} / \mathrm{mL}$ for the polyclonal anti-syndecan- 2 and -3 antibodies.

3. Wash $2 \times$ with TBS containing $0.5 \%$ nonfat dry milk and $0.1 \%$ Tween-20 (30min each). Incubate with HRP-conjugated secondary antibodies (e.g., Jackson Immunoresearch) in TBS containing $0.5 \%$ nonfat dry milk and $0.1 \%$ Tween-20 overnight with agitation at $4{ }^{\circ} \mathrm{C}$. Again, incubation can be shortened to $1-2 \mathrm{~h}$ at room temperature, but overnight incubation at $4^{\circ} \mathrm{C}$ lessens background.

4. Wash $2 \times$ with TBS at room temperature (30min each), develop with ECL reagent (Pierce via Fisher), scan dots, and quantify dot intensity using the public domain NIH Image software. 
5. For Western blotting of intact syndecans, fractionate 100ng of purified samples by $4 \%-15 \%$ SDS-PAGE and Western transfer to Immobilon $\mathrm{Ny}+$ membranes using conventional Tris-Gly-MeOH transfer buffer. Immunoblot for syndecans as described above in steps $2-4$.

6. For Western blotting of native syndecans without GAG chains, incubate 200ng of purified syndecans with $20 \mathrm{mU} / \mathrm{mL}$ heparinase II and $20 \mathrm{mU} / \mathrm{mL}$ chondroitinase $\mathrm{ABC}$ in $50 \mathrm{mM}$ Tris, $\mathrm{pH} 7.5,50 \mathrm{mM} \mathrm{NaOAc}$ for $5 \mathrm{~h}$ at $37^{\circ} \mathrm{C}$. Speed-vac dry samples, resuspend in $1 \times$ SDS-PAGE sample buffer, fractionate by $4 \%-15 \%$ SDS-PAGE, and transfer to PVDF membranes. Immunoblot for syndecans as described in steps $2-4$. When resuspending speed vac-dried syndecans in sample buffer, do not concentrate by more than fivefold. High salt concentrations will distort the syndecan core protein bands. If necessary, concentrate the digested samples by ultrafiltration using a centrifugal device with a MWCO of $10 \mathrm{kDa}$ (e.g., nanosep centrifugal concentrators, Pall Laboratory) prior to resuspending in sample buffer.

\section{FUNCTIONAL ANALYSIS}

\subsection{SYNOPSIS}

GAG chains, especially HS and heparin, bind and regulate a large number of molecules. Thus, proteoglycans such as syndecans are thought to function similarly through their covalently attached HS chains. Indeed, syndecans have been shown to bind to several growth factors, cytokines, chemokines, ECM components, and antimicrobial peptides, among other biomolecules in an HS-dependent manner, and either inhibit or potentiate their activities (Bernfield et al., 1999, 1992; Couchman, 2010; Park et al., 2000). However, syndecans do not interact and regulate all HS/ heparin-binding proteins, indicating that it is important to directly determine the ability of syndecans to bind molecules and to regulate their activities.

Here we describe two in vitro assays where the ability of purified syndecan ectodomains to bind protein ligands and to potentiate the ability of chemokines to induce neutrophil migration is measured. Direct binding of purified syndecans to molecules can be measured in several ways. However, most require relatively large amounts of purified syndecans. A very simple binding assay that requires very low amounts of purified syndecans is the nitrocellulose trap assay. This method takes advantage of the property that highly anionic GAGs and proteoglycans, such as native syndecans, bind poorly to nitrocellulose and bind efficiently to nitrocellulose only when their HS chains are bound to a protein component (Maccarana \& Lindahl, 1993; Noborn et al., 2011). Low ng quantities of purified syndecans are incubated with test proteins for $0.5-2 \mathrm{~h}$, the mixture is dot blotted onto nitrocellulose, and protein binding is measured by immunoblotting for syndecans bound to nitrocellulose (Fig. 2). Specificity of binding can be examined by testing the effects of excess GAGs, sizedefined GAG fragments and modified GAGs (e.g., chemically desulfated), other syndecans, other proteoglycans, or proteins related to the syndecan ligands under study. Fig. 2 shows that purified syndecan-1 ectodomains bind efficiently to FGF-2 and PDGF-AA, but not to PDGF-BB and TNFa, which are all HS/heparin-binding proteins (Abramsson et al., 2007; Feyzi et al., 1997; Kimberley et al., 2009; Rapraeger, Krufka, \& Olwin, 1991; Yayon, 
Klagsbrun, Esko, Leder, \& Ornitz, 1991). In separate studies, we also found that purified syndecan-1 binds to FGF-7, interferon- $\beta$, RANTES (CCL5), and MCP-1 (CCL2), but not to several other heparin/HS-binding growth factors, cytokines, and chemokines such as FGF-1, EGF, HB-EGF, VEGF-165, TGF $\beta$, interferon- $\gamma$, IL-10, IP-10 (CXCL10), and LIX (CXCL5) (not shown). These results are consistent with the differential binding of syndecans to heparin-binding ECM components (Bernfield et al., 1992), and provide additional evidence that native syndecans bind selectively and specifically to heparin/HS-binding proteins.

Another in vitro functional assay that requires low amounts of purified syndecans is measuring the ability of syndecans to potentiate ELR+ CXC chemokine-induced neutrophil chemotaxis. The precise mechanism is not understood, but HSPGs including syndecans can enhance the ability of certain chemokines to induce leukocyte migration at optimal doses. Fig. 3 shows that $1 \mu \mathrm{g} / \mathrm{mL}$ of purified syndecan- 1 and -4 ectodomains enhance mouse neutrophil chemotaxis to $5 \mathrm{ng} / \mathrm{mL}$ of MIP-2 (CXCL2) by more than 70- and 20-fold, respectively. Purified syndecans alone have no effect on neutrophil chemotaxis (Fig. 3), demonstrating that syndecans strictly potentiate the ability of MIP-2 to induce neutrophil migration. Furthermore, heat-treated purified syndecans retain the capacity to potentiate MIP-2-induced neutrophil migration, but heparinase-digested syndecans and recombinant syndecans devoid of GAGs do not possess this activity (not shown), indicating that HS chains mediate the ability of syndecans to potentiate MIP-2 activity. The volume of the bottom chamber of the Transwell plate where purified syndecans are added with chemokines is $600 \mu \mathrm{L}$; thus, only $600 \mathrm{ng}$ of purified syndecans are required to observe the potentiating effects. Furthermore, this assay can be readily modified to examine the ability of purified syndecans to potentiate other chemokines to induce migration of other leukocytes.

\subsection{NITROCELLULOSE TRAP ASSAY}

1. Incubate $1-4 \mathrm{ng}$ of purified syndecan ectodomains with $1-10 \mu \mathrm{g}$ of proteins under study for $0.5-2 \mathrm{~h}$ at room temperature. For purified syndecan-1, 1-4ng of dotblotted ectodomains are not detected by immunoblotting (Fig. 2). We thus incubate $2 \mathrm{ng}$ of purified ectodomains with the experimental proteins for $2 \mathrm{~h}$ at room temperature. Recombinant proteins of various mouse and human HS/ heparin-binding molecules are available from several commercial sources (e.g., Peprotech, R\&D Systems, Biolegend).

2. Insert a nitrocellulose membrane $(0.2 \mu \mathrm{m}$ pore size, Pall Laboratory) and assemble the dot-blot apparatus. Add the experimental mixtures and slowly apply house vacuum.

3. Proceed with immunoblotting and quantification of bound syndecans as described in Section 2.2.4, steps 2-4.

\subsection{POTENTIATION OF CHEMOKINE-INDUCED NEUTROPHIL CHEMOTAXIS}

1. Isolate bone marrow neutrophils from 7- to 10-week-old mice euthanized under an approved IACUC protocol. Both wild-type and various transgenic mouse lines are available from several commercial vendors (e.g., Jackson Laboratory, Charles River Laboratories, Taconic, Harlan Laboratories). Neutrophils can be isolated 
from other tissues (e.g., blood, peritoneal fluid, organs), but the yield $\left(\sim 5 \times 10^{6}\right.$ cells/mouse), purity ( $\searrow 90 \%$ ), and viability ( $\ 95 \%$ ) of naïve neutrophils are highest when isolated from bone marrows. Several papers describe procedures to isolate neutrophils in detail (Boxio, Bossenmeyer-Pourie, Steinckwich, Dournon, \& Nusse, 2004; Hu, 2012; Swamydas, Luo, Dorf, \& Lionakis, 2015), and several isolation kits are also commercially available (e.g., Miltenyi Biotec, Cayman Chemical, Stemcell Technologies). Briefly, in the procedure that we use (Hayashida et al., 2015), femurs and tibias are isolated from euthanized mice, cleaned, and flushed with Hank's Balanced Salt Solution containing 10mM HEPES, $\mathrm{pH}$ 7.4. Bone marrow cells are centrifuged at $300 \times \mathrm{g}$ for $10 \mathrm{~min}$, resuspended in $45 \%$ Percoll solution, layered on top of a $62 \%$ and $81 \%$ Percoll gradient solution, and centrifuged at $1500 \times g$ for $30 \mathrm{~min}$. The neutrophil cell layer between $62 \%$ and $81 \%$ Percoll are collected, washed, resuspended in RPMI-1640, and counted.

2. Prepare 24-well Corning Transwell Plates (Corning) with $3 \mu \mathrm{m}$ filters. Preincubate chemokines and purified syndecans in $600 \mu \mathrm{L}$ of RPMI without serum for 30min and add to the bottom chamber. Add freshly isolated neutrophils to the top chamber in $100 \mu \mathrm{L}$ of RPMI without serum. Allow neutrophils to migrate for $60-180 \mathrm{~min}$ at room temperature. Count the number of migrated cells in the bottom chamber using a hemocytometer. Alternately, neutrophils can be labeled with fluorescent dyes, such as calcein AM (Invitrogen), and migrated cells can be quantified by reading fluorescence with a plate reader.

3. For examining the effects of purified syndecans on MIP-2-induced neutrophil chemotaxis, we add $5 \times 10^{5}$ cells to the top chamber and 1 or $5 \mathrm{ng} / \mathrm{mL}$ MIP-2 to the bottom chamber without or with $1 \mu \mathrm{g} / \mathrm{mL}$ purified syndecans and measure migration over 80min (Fig. 3). Syndecans also enhance the ability of other ELR+ CXC chemokines, such as KC (CXCL1) and LIX (CXCL5), to induce neutrophil migration. However, the potentiating activity of both syndecan- 1 and -4 ectodomains is the highest for MIP-2. Note that in this assay the highest concentration of MIP-2 that does not induce significant neutrophil migration and the lowest concentration of purified syndecans that potentiates MIP-2-induced neutrophil migration were titrated in preliminary experiments. Syndecans at concentrations lower than $0.5 \mu \mathrm{g} / \mathrm{mL}$ or over $10 \mu \mathrm{g} / \mathrm{mL}$ do not enhance MIP-2induced neutrophil migration.

4. Also note that isolated neutrophils are viable for $\sim 5-6 \mathrm{~h}$ so the whole assay must be performed within this time frame. When testing the effects of purified syndecans on other chemokines and other leukocytes, titrate the optimal doses of chemokines and syndecans, optimal number of leukocytes, and optimal size of filters in preliminary experiments. Furthermore, in the first few titration experiments, leukocytes attached to the filter surface on the top and bottom surfaces and in the pores should be quantified in addition to leukocytes that have migrated into the bottom chamber. 


\subsection{OTHER IN VITRO AND IN VIVO FUNCTIONAL ASSAYS}

There are several other methods to examine the binding properties and biological functions of purified native syndecans. For example, affinity coelectrophoresis can measure both the binding affinity and structural selectivity of syndecan-protein-binding interactions (Kato et al., 1994; Lee \& Lander, 1991; Zako et al., 2003). This assay is based on the principle that the mobility of syndecans will be retarded in agarose gels embedded with different concentrations of syndecan-binding ligands. The relative migration distance is plotted to determine the affinity of syndecans for the particular protein.

Purified syndecan-1 ectodomains bind and inhibit the capacity of several AMPs to kill bacterial pathogens in an HS-dependent manner (Hayashida et al., 2015; Park et al., 2001). Briefly, the effects of purified syndecans on bacterial killing by AMPs can be determined by incubating bacteria (e.g., Staphylococcus aureus, Pseudomonas aeruginosa from ATCC) with AMPs (e.g., LL-37, CRAMP from Anaspec) without or with increasing doses of purified syndecans, and measuring bacterial survival by plating serial dilutions on nutrient agar plates and counting bacterial colonies (Hayashida et al., 2015; Jinno \& Park, 2015).

Purified syndecan- 1 ectodomains have also been shown to either improve or worsen the outcome of several sterile and infectious inflammatory diseases in mice (Teng et al., 2012). For example, administration of ng to low $\mu \mathrm{g}$ quantities of syndecan-1 ectodomains attenuates inflammatory tissue injury in mouse models of endotoxic shock (Hayashida, Parks, et al., 2009), Gram-positive toxic shock (Hayashida et al., 2008), and allergic lung disease (Xu et al., 2005), whereas administration of low amounts of syndecan- 1 ectodomains promotes pathogenesis in mouse models of bacterial lung (Park et al., 2001), skin (Haynes et al., 2005), and eye (Hayashida, Amano, \& Park, 2011) infection. Syndecans are thought to be important in many other infectious and inflammatory diseases, such as colitis, nephritis, myocardial infarction, malaria, and several sexually transmitted diseases (Teng et al., 2012), but the potential beneficial or detrimental effects of purified syndecans have not been studied in these diseases.

\section{Acknowledgments}

We would like to thank past and current members of the Park Laboratory for developing essential reagents and constantly refining the described procedures. This work was supported by NIH grants R01 EY021765, R01 HL132573, and R21 AI126844. The author declares no conflict of interests.

\section{References}

Abramsson A, Kurup S, Busse M, Yamada S, Lindblom P, Schallmeiner E, et al. Defective $N$-sulfation of heparan sulfate proteoglycans limits PDGF-BB binding and pericyte recruitment in vascular development. Genes \& Development. 2007; 21:316-331. [PubMed: 17289920]

Alexander CM, Reichsman F, Hinkes MT, Lincecum J, Becker KA, Cumberledge S, et al. Syndecan-1 is required for Wnt-1-induced mammary tumorigenesis in mice. Nature Genetics. 2000; 25:329_ 332. [PubMed: 10888884]

Bernfield M, Götte M, Park PW, Reizes O, Fitzgerald ML, Lincecum J, et al. Functions of cell surface heparan sulfate proteoglycans. Annual Review of Biochemistry. 1999; 68:729-777.

Bernfield M, Kokenyesi R, Kato M, Hinkes MT, Spring J, Gallo RL, et al. Biology of the syndecans: A family of transmembrane heparan sulfate proteoglycans. Annual Review of Cell Biology. 1992; 8:365-393. 
Bishop JR, Schuksz M, Esko JD. Heparan sulphate proteoglycans fine-tune mammalian physiology. Nature. 2007; 446:1030-1037. [PubMed: 17460664]

Boxio R, Bossenmeyer-Pourie C, Steinckwich N, Dournon C, Nusse O. Mouse bone marrow contains large numbers of functionally competent neutrophils. Journal of Leukocyte Biology. 2004; 75:604611. [PubMed: 14694182]

Couchman JR. Transmembrane signaling proteoglycans. Annual Review of Cell and Developmental Biology. 2010; 26:89-114.

Dews IC, Mackenzie KR. Transmembrane domains of the syndecan family of growth factor coreceptors display a hierarchy of homotypic and heterotypic interactions. Proceedings of the National Academy of Sciences of the United States of America. 2007; 104:20782-20787. [PubMed: 18093920]

Echtermeyer F, Streit M, Wilcox-Adelman S, Saoncella S, Denhez F, Detmar M, et al. Delayed wound repair and impaired angiogenesis in mice lacking syndecan-4. The Journal of Clinical Investigation. 2001; 107:R9-R14. [PubMed: 11160142]

Elenius K, Salmivirta M, Inki P, Mali M, Jalkanen M. Binding of human syndecan to extracellular matrix proteins. The Journal of Biological Chemistry. 1990; 265:17837-17843. [PubMed: 1698781]

Feyzi E, Lustig F, Fager G, Spillmann D, Lindahl U, Salmivirta M. Characterization of heparin and heparan sulfate domains binding to the long splice variant of platelet-derived growth factor $\mathrm{A}$ chain. The Journal of Biological Chemistry. 1997; 272:5518-5524. [PubMed: 9038157]

Fujikura D, Ikesue M, Endo T, Chiba S, Higashi H, Uede T. Death receptor 6 contributes to autoimmunity in lupus-prone mice. Nature Communications. 2017; 8:13957.

Hayashi K, Hayashi M, Jalkanen M, Firestone JH, Trelstad RL, Bernfield M. Immunocytochemistry of cell surface heparan sulfate proteoglycan in mouse tissues. A light and electron microscopic study. The Journal of Histochemistry and Cytochemistry: Official Journal of the Histochemistry Society. 1987; 35:1079-1088. [PubMed: 2957423]

Hayashida A, Amano S, Gallo RL, Linhardt RJ, Liu J, Park PW. 2-O-sulfated domains in syndecan-1 heparan sulfate inhibit neutrophil cathelicidin and promote Staphylococcus aureus corneal infection. The Journal of Biological Chemistry. 2015; 290:16157-16167. [PubMed: 25931123]

Hayashida A, Amano S, Park PW. Syndecan-1 promotes Staphylococcus aureus corneal infection by counteracting neutrophil-mediated host defense. The Journal of Biological Chemistry. 2011; 285:3288-3297.

Hayashida A, Bartlett AH, Foster TJ, Park PW. Staphylococcus aureus beta-toxin induces acute lung injury through syndecan-1. The American Journal of Pathology. 2009; 174:509-518. [PubMed: 19147831]

Hayashida K, Chen Y, Bartlett AH, Park PW. Syndecan-1 is an in vivo suppressor of Gram-positive toxic shock. The Journal of Biological Chemistry. 2008; 283:19895-19903. [PubMed: 18499671]

Hayashida K, Parks WC, Park PW. Syndecan-1 shedding facilitates the resolution of neutrophilic inflammation by removing sequestered CXC chemokines. Blood. 2009; 114:3033-3043. [PubMed: 19638625]

Haynes A 3rd, Ruda F, Oliver J, Hamood AN, Griswold JA, Park PW, et al. Syndecan-1 shedding contributes to Pseudomonas aeruginosa sepsis. Infection and Immunity. 2005; 73:7914-7921. [PubMed: 16299282]

$\mathrm{Hu}$ Y. Isolation of human and mouse neutrophils ex vivo and in vitro. Methods in Molecular Biology. 2012; 844:101-113. [PubMed: 22262437]

Ishiguro K, Kadomatsu K, Kojima T, Muramatsu H, Iwase M, Yoshikai Y, et al. Syndecan-4 deficiency leads to high mortality of lipopolysaccharide-injected mice. The Journal of Biological Chemistry. 2001; 276:47483-47488. [PubMed: 11585825]

Jinno A, Park PW. Role of glycosaminoglycans in infectious disease. Methods in Molecular Biology. 2015; 1229:567-585. [PubMed: 25325982]

Kato M, Wang H, Bernfield M, Gallagher JT, Turnbull JE. Cell surface syndecan-1 on distinct cell types differs in fine structure and ligand binding of its heparan sulfate chains. The Journal of Biological Chemistry. 1994; 269:18881-18890. [PubMed: 8034644] 
Kharabi Masouleh B, Ten Dam GB, Wild MK, Seelige R, van der Vlag J, Rops AL, et al. Role of the heparan sulfate proteoglycan syndecan-1 (CD138) in delayed-type hypersensitivity. Journal of Immunology. 2009; 182:4985-4993.

Kim CW, Goldberger OA, Gallo RL, Bernfield M. Members of the syndecan family of heparan sulfate proteoglycans are expressed in distinct cell-, tissue-, and development-specific patterns. Molecular Biology of the Cell. 1994; 5:797-805. [PubMed: 7812048]

Kimberley FC, van Bostelen L, Cameron K, Hardenberg G, Marquart JA, Hahne M, et al. The proteoglycan (heparan sulfate proteoglycan) binding domain of APRIL serves as a platform for ligand multimerization and cross-linking. The FASEB Journal. 2009; 23:1584-1595. [PubMed: 19141538]

Kjellen L, Pettersson I, Hook M. Cell-surface heparan sulfate: An intercalated membrane proteoglycan. Proceedings of the National Academy of Sciences of the United States of America. 1981; 78:5371-5375. [PubMed: 6458040]

Lee MK, Lander AD. Analysis of affinity and structural selectivity in the binding of proteins to glycosaminoglycans: Development of a sensitive electrophoretic approach. Proceedings of the National Academy of Sciences of the United States of America. 1991; 88:2768-2772. [PubMed: 1901416]

Li Q, Park PW, Wilson CL, Parks WC. Matrilysin shedding of syndecan-1 regulates chemokine mobilization and transepithelial efflux of neutrophils in acute lung injury. Cell. 2002; 111:635646. [PubMed: 12464176]

Maccarana M, Lindahl U. Mode of interaction between platelet factor 4 and heparin. Glycobiology. 1993; 3:271-277. [PubMed: 8358152]

Maday S, Anderson E, Chang HC, Shorter J, Satoh A, Sfakianos J, et al. A PDZ-binding motif controls basolateral targeting of syndecan-1 along the biosynthetic pathway in polarized epithelial cells. Traffic. 2008; 9:1915-1924. [PubMed: 18764819]

Noborn F, O'Callaghan P, Hermansson E, Zhang X, Ancsin JB, Damas AM, et al. Heparan sulfate/ heparin promotes transthyretin fibrillization through selective binding to a basic motif in the protein. Proceedings of the National Academy of Sciences of the United States of America. 2011; 108:5584-5589. [PubMed: 21422279]

Park PW, Pier GB, Hinkes MT, Bernfield M. Exploitation of syndecan-1 shedding by Pseudomonas aeruginosa enhances virulence. Nature. 2001; 411:98-102. [PubMed: 11333985]

Park PW, Reizes O, Bernfield M. Cell surface heparan sulfate proteoglycans: Selective regulators of ligand-receptor encounters. The Journal of Biological Chemistry. 2000; 275:29923-29926. [PubMed: 10931855]

Rapraeger AC, Bernfield M. Heparan sulfate proteoglycans from mouse mammary epithelial cells. A putative membrane proteoglycan associates quantitatively with lipid vesicles. The Journal of Biological Chemistry. 1983; 258:3632-3636. [PubMed: 6219993]

Rapraeger AC, Krufka A, Olwin BB. Requirement of heparan sulfate for bFGF-mediated fibroblast growth and myoblast differentiation. Science. 1991; 252:1705-1708. [PubMed: 1646484]

Rops AL, Gotte M, Baselmans MH, van den Hoven MJ, Steenbergen EJ, Lensen JF, et al. Syndecan-1 deficiency aggravates antiglomerular basement membrane nephritis. Kidney International. 2007; 72:1204-1215. [PubMed: 17805240]

Salmivirta M, Elenius K, Vainio S, Hofer U, Chiquet-Ehrismann R, Thesleff I, et al. Syndecan from embryonic tooth mesenchyme binds tenascin. The Journal of Biological Chemistry. 1991; 266:7733-7739. [PubMed: 1708391]

Saunders S, Bernfield M. Cell surface proteoglycan binds mouse mammary epithelial cells to fibronectin and behaves as a receptor for interstitial matrix. The Journal of Cell Biology. 1988; 106:423-430. [PubMed: 2963012]

Saunders S, Jalkanen M, O'Farrell S, Bernfield M. Molecular cloning of syndecan, an integral membrane proteoglycan. The Journal of Cell Biology. 1989; 108:1547-1556. [PubMed: 2494194]

Sun X, Mosher DF, Rapraeger A. Heparan sulfate-mediated binding of epithelial cell surface proteoglycan to thrombospondin. The Journal of Biological Chemistry. 1989; 264:2885-2889. [PubMed: 2521631] 
Sutherland AE, Sanderson RD, Mayes M, Seibert M, Calarco PG, Bernfield M, et al. Expression of syndecan, a putative low affinity fibroblast growth factor receptor, in the early mouse embryo. Development. 1991; 113:339-351. [PubMed: 1765004]

Swamydas M, Luo Y, Dorf ME, Lionakis MS. Isolation of mouse neutrophils. Current Protocols in Immunology. 2015; 110:3.20.21-23.20.15. [PubMed: 26237011]

Teng YH, Aquino RS, Park PW. Molecular functions of syndecan-1 in disease. Matrix Biology. 2012; 31:3-16. [PubMed: 22033227]

Vanhoutte D, Schellings MW, Gotte M, Swinnen M, Herias V, Wild MK, et al. Increased expression of syndecan-1 protects against cardiac dilatation and dysfunction after myocardial infarction. Circulation. 2007; 115:475-482. [PubMed: 17242279]

Wijdenes J, Vooijs WC, Clement C, Post J, Morard F, Vita N, et al. A plasmocyte selective monoclonal antibody (B-B4) recognizes syndecan-1. British Journal of Haematology. 1996; 94:318-323. [PubMed: 8759892]

Xu J, Park PW, Kheradmand F, Corry DB. Endogenous attenuation of allergic lung inflammation by syndecan-1. Journal of Immunology. 2005; 174:5758-5765.

Yayon A, Klagsbrun M, Esko JD, Leder P, Ornitz DM. Cell surface, heparin-like molecules are required for binding of basic fibroblast growth factor to its high affinity receptor. Cell. 1991; 64:841-848. [PubMed: 1847668]

Zako M, Dong J, Goldberger O, Bernfield M, Gallagher JT, Deakin JA. Syndecan-1 and -4 synthesized simultaneously by mouse mammary gland epithelial cells bear heparan sulfate chains that are apparently structurally indistinguishable. The Journal of Biological Chemistry. 2003; 278:1356113569. [PubMed: 12571251] 
A

25

20 15

150

100

75

50

37
Intact PG
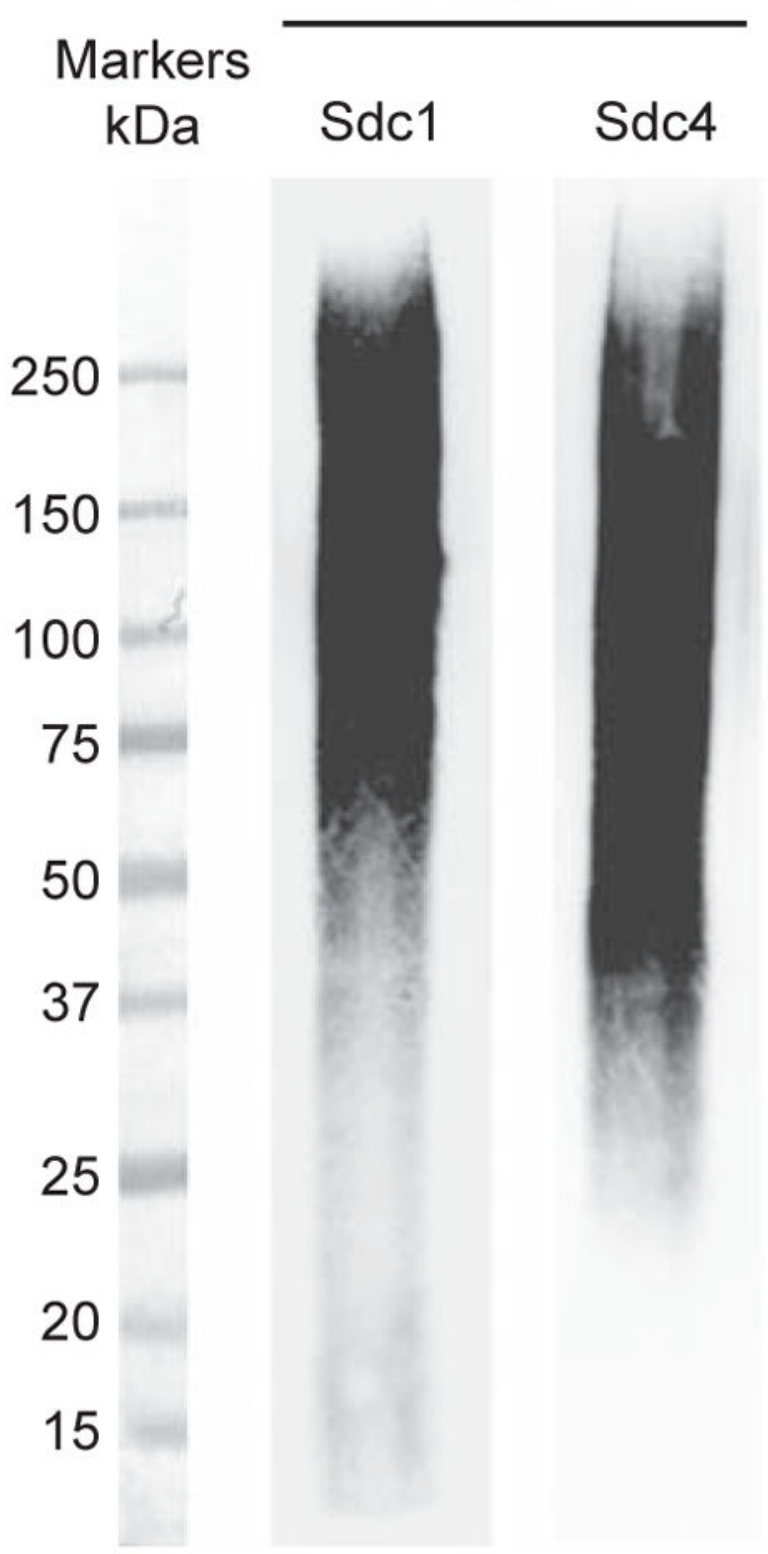

B
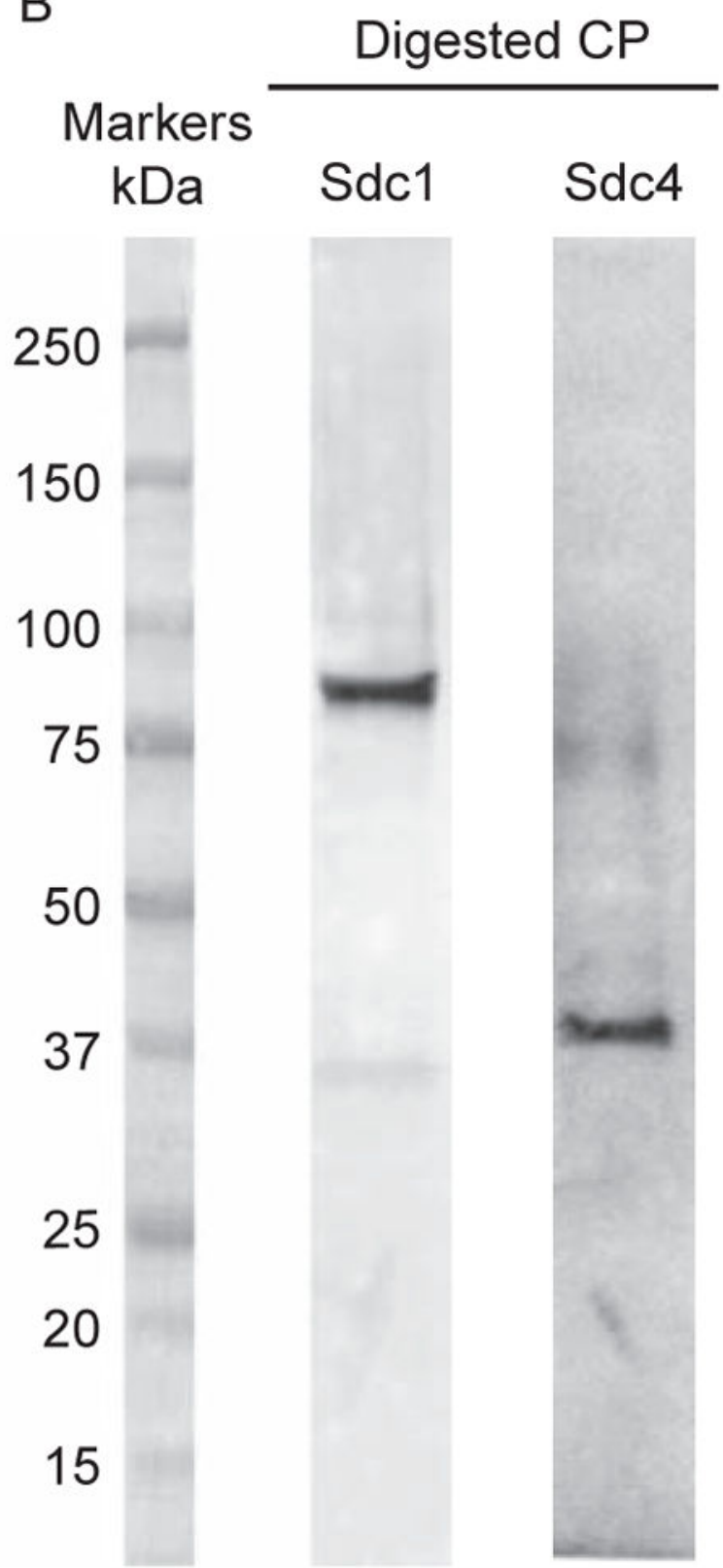

FIG. 1.

Western immunoblot of intact and heparinase II- and chondroitinase ABC-digested purified syndecan-1 and -4 ectodomains. (A) Purified syndecan-1 and -4 ectodomains (100ng) were separated by $4 \%-15 \%$ SDS-PAGE under reducing conditions, Western transferred to an Immobilon $\mathrm{Ny}+$ membrane, and immunoblotted using the 281-2 rat monoclonal anti-mouse syndecan-1 or Ky8.2 rat monoclonal anti-mouse syndecan-4 antibodies. (B) Purified syndecan-1 and -4 ectodomains (200ng) were digested with $20 \mathrm{mU} / \mathrm{mL}$ heparinase II and $20 \mathrm{mU} / \mathrm{mL}$ chondroitinase ABC, speed-vac dried, resuspended in $1 \times$ SDS sample buffer, separated by $4 \%-15 \%$ SDS-PAGE under reducing conditions, transferred to a PVDF 
membrane, and immunoblotted using the 281-2 rat monoclonal anti-mouse syndecan-1 or Ky8.2 rat monoclonal anti-mouse syndecan- 4 antibodies. 

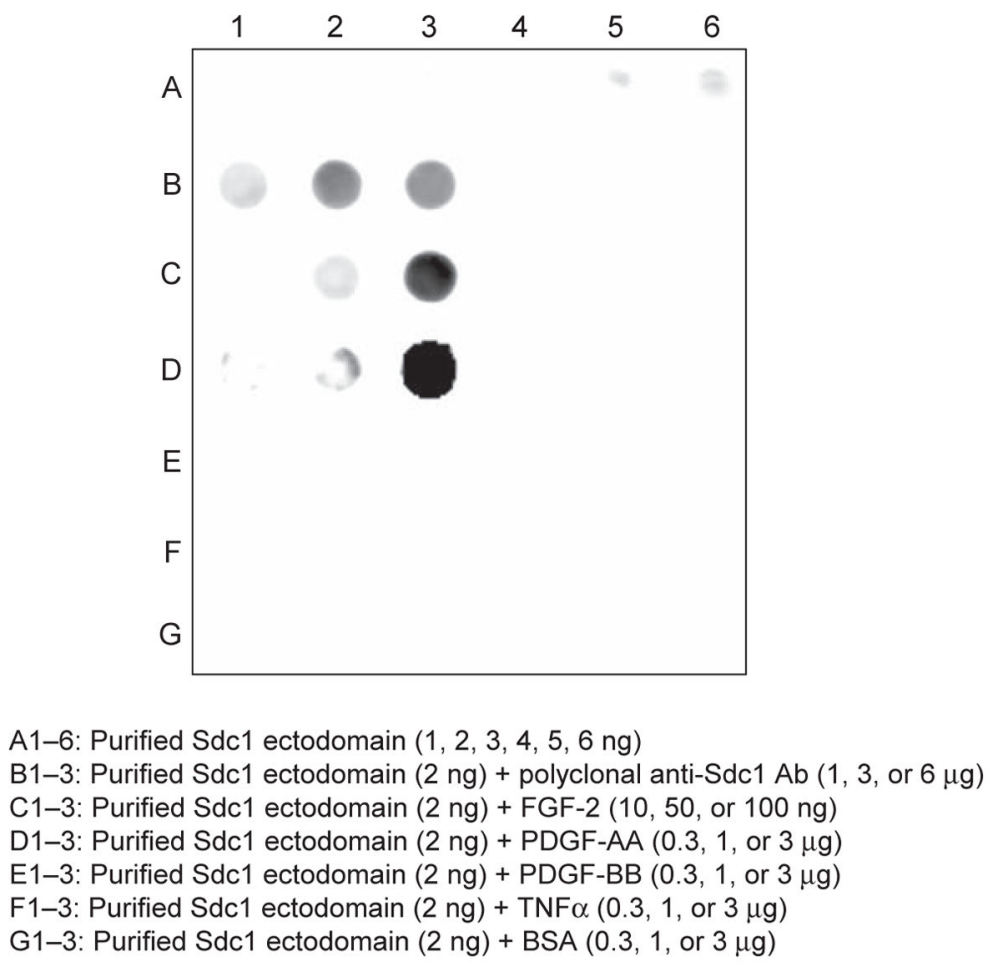

FIG. 2.

Binding of purified syndecan-1 ectodomains to HS/heparin-binding molecules by nitrocellulose trap assay. In row A, 1-6ng of purified syndecan-1 ectodomains in 50 $\mu \mathrm{L}$ PBS were dot blotted onto nitrocellulose (A1-6). In rows B-G, 2ng of purified syndecan-1 ectodomains were incubated with 1,3 , or $6 \mu \mathrm{g}$ of rabbit polyclonal anti-mouse syndecan-1 antibodies, which serve as a positive control (B1-3), 10, 50, or 100ng of FGF-2 (C1-3), or $0.3,1$, or $3 \mu$ g of PDGF-AA (D1-3), PDGF-BB (E1-3), TNFa (F1-3), or BSA (G1-3) in $50 \mu \mathrm{L}$ PBS for $2 \mathrm{~h}$ at room temperature and dot blotted onto nitrocellulose. Syndecan-1 bound to nitrocellulose was visualized by immunoblotting with 281-2 rat monoclonal anti-mouse syndecan-1 antibodies. 


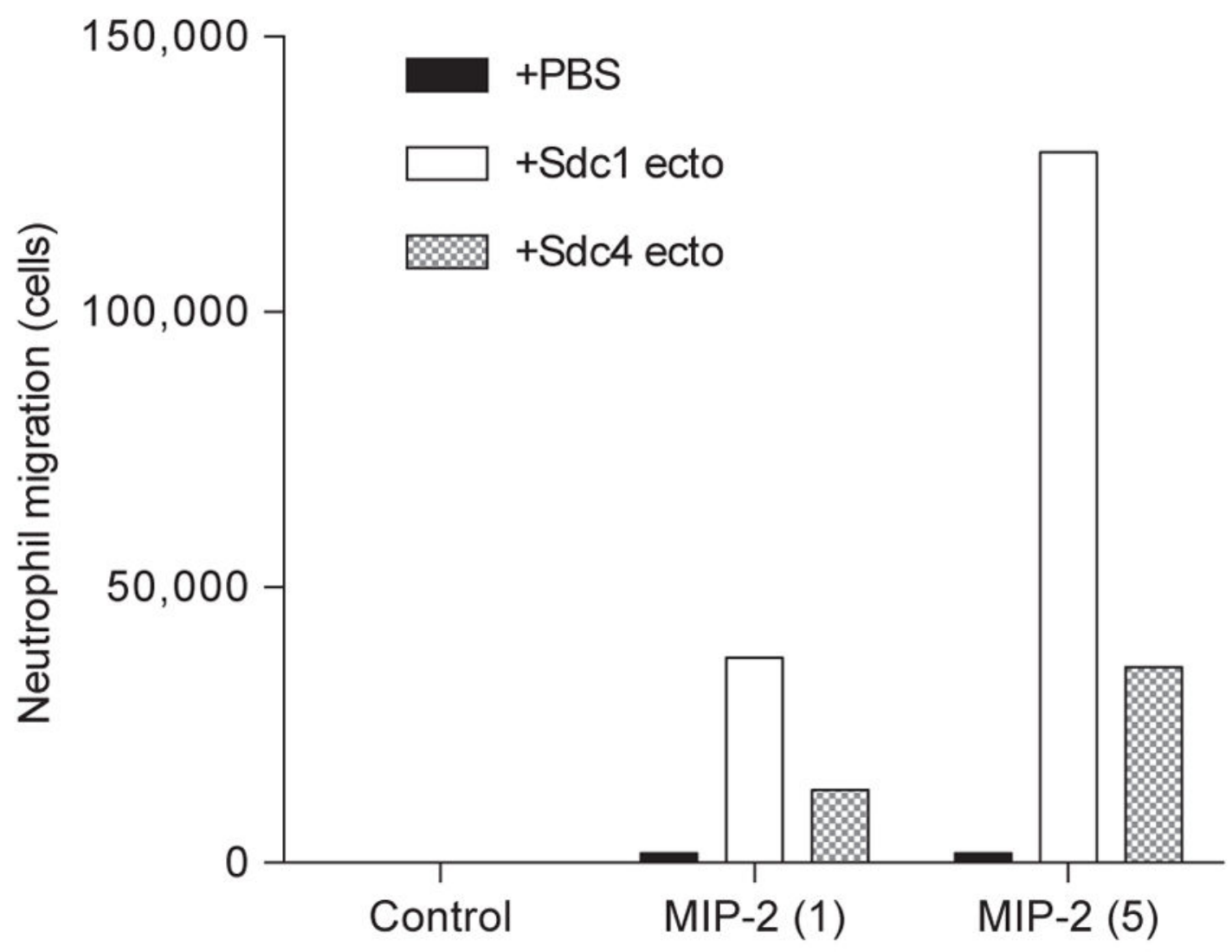

FIG. 3.

Potentiation of MIP-2-induced neutrophil chemotaxis by purified syndecan-1 and -4 ectodomains. Chemotaxis of mouse bone marrow neutrophils $\left(5 \times 10^{5}\right.$ cells) to PBS (control) or 1 or $5 \mathrm{ng} / \mathrm{mL}$ MIP-2 preincubated without or with $1 \mu \mathrm{g} / \mathrm{mL}$ purified syndecan- 1 or -4 ectodomains placed in the lower chamber of a Corning Transwell plate was measured over $80 \mathrm{~min}$ at room temperature. 